\title{
DINÂMICAS DE REGENERAÇÃO, DEGENERAÇÃO E DESMATAMENTO DA VEGETAÇÃO PROVOCADAS POR FATORES CLIMÁTICOS E GEOMORFOLÓGICOS: UMA ANÁLISE GEOECOLÓGICA ATRAVÉS DE SIG ${ }^{1}$
}

\author{
Carla Semiramis Silveira² e Viviane Vidal da Silva ${ }^{3}$
}

\begin{abstract}
RESUMO - Este trabalho teve como objetivo analisar a influência de fatores climáticos (insolação e precipitação anual) e geomorfológicos (declividade) na dinâmica das transformações da cobertura vegetal arbórea e no uso do solo. A área de pesquisa é a bacia hidrográfica do rio Paquequer, região serrana do Estado do Rio de Janeiro, bacia representativa de Mata Atlântica. Foram utilizadas as interpretações da cobertura vegetal dos anos de 1976 e 1996, obtidas, respectivamente, através de fotografias aéreas e imagem de satélite SPOT-3 XS/PAN. Os dados de relevo e de insolação (aspect) foram derivados do Projeto Teresópolis (UERJ/IBGE) e os de pluviosidade, da CPRM. A análise da dinâmica da cobertura vegetal arbórea em 20 anos visou avaliar os fatores físicos condicionantes de processos de regeneração (inicial e avançada), degeneração e de desmatamento. Essas categorias de informação foram cruzadas com os fatores de declividade, insolação e precipitação anual. A análise espacial foi realizada com o uso de Sistema de Informação Geográfica (SIG), utilizando-se o software ArcGIS 9.0. Enquanto a regeneração inicial ocorre indistintamente dos fatores abióticos, sugere-se que a regeneração avançada seja um processo mais seletivo, ou melhor, preferencialmente em encostas com menor insolação e mais úmidas. De forma contrária, o desmatamento da vegetação para uso antrópico tende a ser mais intenso nas áreas favoráveis ao uso: baixa declividade e maior insolação (encostas voltadas para o norte).
\end{abstract}

Palavras-chave: Geoprocessamento, Geoecologia e Uso do solo.

\section{NATURAL REGENERATION, DEGENERATION AND DEFORESTATION DYNAMICS CONTROLLED BY CLIMATIC AND GEOMORPHIC PARAMETERS: A GEOCOLOGICAL ANALYSIS USING GIS}

\begin{abstract}
The purpose of this paper was to evaluate the influence of climate (insolation and annual precipitation) and relief (slope) on the land use and forest changes in a mountainous watershed (Paquequer / RJ) representative of the Atlantic Forest. Land use thematic maps for different dates (1976 and 1996) were derived from aerial photographs and SPOT-3 XS/PAN image. Land use and natural regeneration changes in 20 years were classified as initial natural regeneration, late natural regeneration, degeneration and deforestation. GIS spatial informations were dealt with ArcGIS 9.0. While initial regeneration occurs indistinctly of the climatic and relief parameters, it is suggested that advanced regeneration is a more selective process. That is, advanced regeneration occurs mainly in areas with less insolation and higher humidity. On the other hand, the deforestation for human use tends to be more intense in lower and greater insolation slopes (toward north).
\end{abstract}

Keywords: Geoprocessing, Geoecology and Land use.

\footnotetext{
${ }^{1}$ Recebido em 12.07.2008 e aceito para publicação em 25.08.2010.

${ }^{2}$ Universidade Federal Fluminense, UFF, Brasil. E-mail: <carla@geoq.uff.br>.

${ }^{3}$ Universidade Federal do Amazonas, UFAM, Brasil. E-mail: <silvavv@gmail.com>.
} 


\section{INTRODUÇÃO}

A configuração espacial dos diferentes elementos que compõem uma paisagem (habitats e tipos de uso) e suas mudanças através do tempo podem ser atribuídas a uma combinação entre desenvolvimento ambiental e à influência humana (DUNN et al., 1991). O entendimento da interação entre os fatores físicos, antrópicos e da cobertura vegetal em uma paisagem é de fundamental importância para oferecer subsídios ao planejamento territorial de forma sustentável.

Em função da extensão de atuação dos processos ambientais, o sensoriamento remoto e os sistemas de informação geográficas (SIG) têm sido utilizados como ferramenta de suporte na análise ambiental (NASCIMENTO et al., 2006; FIDALGO etal., 2003; JORGE e SARTORI, 2002). A capacidade sinergística dessas tecnologias é fundamental para conectar propriedades espacialmente distribuídas e fornecer novas informações interpretativas (BURROUGH e MCDONNELL, 2006).

Segundo GUERRA (1994), a declividade, o comprimento e a forma da encosta são fatores que afetam a erodibilidade dos solos. Fatores relacionados às características das chuvas e às propriedades dos solos, como porosidade e resistência de agregados, também influenciam o funcionamento hidrológico da encosta. A resultante hidrológica da integração entre as características do solo e da chuva é a que, em última análise, determina o tipo e a intensidade dos processos erosivos (GUERRA, 1994; COELHO NETTO, 1994). Estudos hidrogeoquímicos também mostram que há variabilidade espacial entre a composição da água do topo do solo em relação a nutrientes na encosta, sendo a disponibilidade de nutrientes mais efetiva nas áreas de vale do que nas maiores declividades. Isso ocorre porque as áreas de maior declividade são muito mais suscetíveis à erosão, perdendo nutrientes através da lixiviação (FILGUEIRA LEITE et al., 1997). Em uma área de reflorestamento, CHADA et al. (2004) indicaram que a sucessão vegetal evolui mais rapidamente nas menores declividades. JORGE e SARTORI(2002) também obtiveram boa correlação entre características de relevo e solos (relevo ondulado - frente de cuestas e Neossolos Litólicos) e processos de regeneração de Floresta Estacional Semidecidual em 19 anos. Esses resultados enfatizam a importância do Código Florestal que estabelece a manutenção da vegetação florestal em encostas com declividade acima de $45^{\circ}$ (ou $50 \%$ considerando $90^{\circ}$ como $100 \%$ de declividade).
A Mata Atlântica constitui um complexo de tipos florestais que se desenvolve ao longo da costa do Brasil, desde o Estado do Rio Grande do Norte até o Rio Grande do Sul, o que correspondia, primariamente, à cerca de $15 \%$ do território brasileiro. Entre os ecossistemas brasileiros, a Mata Atlântica é a que mais sofreu, e vem sofrendo, intensos e persistentes processos de degradação e fragmentação florestal, restando apenas $7 \%$ da cobertura original. Esses fragmentos florestais remanescentes são importantes fontes de irradiação e colonização de áreas adjacentes e contribuem para a heterogeneidade espacial e a estabilidade da paisagem (FUNDAÇÃO SOS MATA ATLÂNTICA/INPE, 2006). Aregeneração natural florestal é o processo de recuperação de uma floresta a partir de um distúrbio natural ou antrópico. É um processo lento de sucessão vegetal dependente de diversos fatores, como fonte de sementes, condições ambientais e intensidade e duração do distúrbio. Em condições favoráveis, a vegetação é, então, conduzida para estágios sucessionais mais avançados, modificando as condições ecológicas até alcançar um nível estável clímax. De forma inversa, uma vegetação pode sofrer degeneração para estágios sucessionais menos avançados por condicionantes ambientais e, ou, antrópicas. O conhecimento sobre os fatores favoráveis para a regeneração natural/degeneração é pertinente para estabelecer taxas de renovação desse recurso natural e possíveis condições de manejo de florestas (SOUZA et al., 2002).

O Município de Teresópolis está situado em uma área originalmente de Mata Atlântica. Entretanto, a proximidade com o Município do Rio de Janeiro tem possibilitado, desde o século XIX, a sua utilização como área de veraneio e turismo, sendo alvo de desflorestamentos para a cultura do café, não satisfatoriamente implantada e posteriormente substituída pela criação de gado (ROCHA, 1999). Em 1949 foram criados o Parque Nacional da Serra dos Órgãos e as Áreas de Proteção Ambiental Floresta do Jacarandá e da Bacia dos Frades, com o objetivo de preservar a Mata Atlântica naquele município.

Atualmente, a concentração urbana tem produzido profundas alterações na paisagem, decorrentes das transformações na forma de ocupação e uso do solo urbano, do processo de especulação imobiliária e valorização das áreas centrais, configurando-se um novo arranjo espacial (COSTA, 2004). 
Para avaliar a dinâmica dos fragmentos florestais da Mata Atlântica no Município de Teresópolis, foi selecionada a Bacia Hidrográfica do Rio Paquequer como área de pesquisa. Este trabalho teve como objetivo analisar a influência de fatores abióticos (clima e relevo) na dinâmica de transformação da cobertura vegetal arbórea e uso da terra. Dessa forma, pretendeu-se identificar os condicionantes físicos que sejam favoráveis aos processos de regeneração e degeneração da vegetação e de desmatamento. Para essa análise foi definido um período de 20 anos (1976-1996), no qual a vegetação foi classificada em estágios de regeneração e uso, e os fatores físicos de clima (precipitação anual e insolação/orientação das vertentes) e de relevo (declividade). A metodologia utilizada foi baseada em cruzamentos de informações espacialmente georreferenciadas, utilizando-se Sistemas de Informação Geográfica e estabelecendo cinco classes de dinâmica detalhadas a seguir (desmatamento, degeneração, regeneração inicial, regeneração avançada e sem modificações). A partir dos resultados desses cruzamentos foi feita uma análise das possíveis causas da dinâmica de transformação da cobertura vegetal/uso da área para um período de 20 anos.

Análises utilizando metodologia similar com geoprocessamento e sensoriamento remoto também foram feitas para avaliação da dinâmica de transformação da vegetação florestal em um intervalo de tempo (JORGE e SARTORI, 2002), de avaliação de potencialidades de uso do solo (FIDALGO et al., 2003) e descrição de fragmentos florestais (NASCIMENTO et al., 2006). Esses trabalhos enfatizaram a aplicação de SIG para monitoramento e planejamento ambiental.

\section{MATERIAL E MÉTODOS}

\section{1 Área de estudo}

A Bacia Hidrográfica do Rio Paquequer localiza-se no Município de Teresópolis, região Serrana (Serra do Mar) do Estado do Rio de Janeiro, entre as coordenadas $43^{\circ} 03^{\prime} 19^{\prime \prime}$ a $42^{\circ} 55^{\prime} 00^{\prime \prime}$ de longitude Oeste e $22^{\circ} 28^{\prime} 35^{\prime \prime}$ a $22^{\circ} 12^{\prime} 56^{\prime \prime}$ de latitude Sul, totalizando uma área de $269 \mathrm{~km}^{2}$ (Figura 1). Abrange os distritossede de Teresópolis e Vale do Paquequer Pequeno.

O clima é caracterizado por temperaturas médias em torno de $18{ }^{\circ} \mathrm{C}$ e pluviosidade com médias anuais de $1.500 \mathrm{~mm}$ (a jusante da bacia) a $2.500 \mathrm{~mm}$ (nas cabeceiras) e chuvas predominando no verão (SILVA, 2004; SILVA et al., 2006).

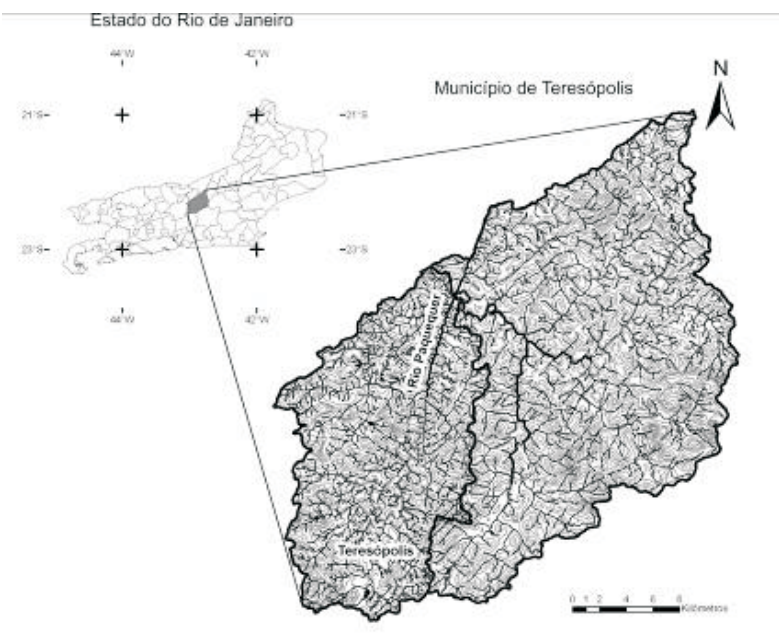

Figura 1 - Localização da área de estudo (bacia do rio Paquequer), no Município de Teresópolis e no Estado do Rio de Janeiro.

Figure 1 - Location of study area (Paquequer watershed) in Teresópolis municipality and in the State of Rio de Janeiro.

Fisiograficamente predomina o relevo montanhoso e escarpado com vales encaixados. As unidades geológicas são basicamente constituídas de gnaisses e granitos. Os solos são predominantemente Cambissolos e Latossolos Vermelho-Amarelos nos interflúvios, enquanto nas várzeas predominam os Gleissolos e os solos aluviais (UERJ/IBGE, 1999).

A cobertura vegetal natural na região faz parte do ecossistema Mata Atlântica, sob domínio de Floresta Ombrófila Densa Montana e Alto-Montana (SILVA, 2004).

A população da bacia apresenta perfil predominantemente urbano (96,3\%) e concentrada no distrito-sede, Teresópolis. Secundariamente, há um contingente populacional rural associado à atividade olerícola no Distrito do Vale do Paquequer Pequeno (COSTA, 2004).

\subsection{Base de dados}

Para analisar a dinâmica de regeneração, de desmatamento e de degeneração, em escala 1:50.000, da vegetação da Bacia do Paquequer, no período de 20 anos, foi utilizada a base de dados em ambiente de Sistema de Informação Geográfica (SIG) do Projeto

Revista Árvore, Viçosa-MG, v.34, n.6, p.1025-1034, 2010 
Teresópolis (UERJ/IBGE, 1999). Desse projeto foram selecionadas as categorias de informação: cobertura vegetal e uso do solo em 1976 e 1996. Abase cartográfica e a hidrografia foram originadas de cartas 1:50.000 do IBGE já digitalizadas dentro do escopo do Projeto Teresópolis. Também, foi utilizada a distribuição de chuvas (isoetas) geradas pela CPRM para a região (CPRM, 2004).

A categoria de informação cobertura vegetal do ano de 1976 foi confeccionada a partir de interpretação visual de fotografias áreas na escala de 1:40.000, enquanto a do ano de 1996 contou com a interpretação visual da imagem de satélite SPOT-3 XS/PAN, composição colorida, banda 1(R), 3(G) e 2(B), em resolução espacial de $10 \mathrm{~m}$, e trabalhos de campo na época (Figura 2). Apesar de os mapas serem produtos provenientes de fontes distintas, a foto aérea nessa escala tem resolução de $8 \mathrm{~m}$ (considera-se $0,2 \mathrm{~mm}$ a acurácia visual), que pode, então, ser comparada com a imagem SPOT de 10 m de resolução. A resolução de $10 \mathrm{~m}$ pressupõe a escala 1:50.000, que foi a utilizada nas análises desenvolvidas. Vale ressaltar que em 1976 a fotografia aérea era o único formato disponível de imagem do local.

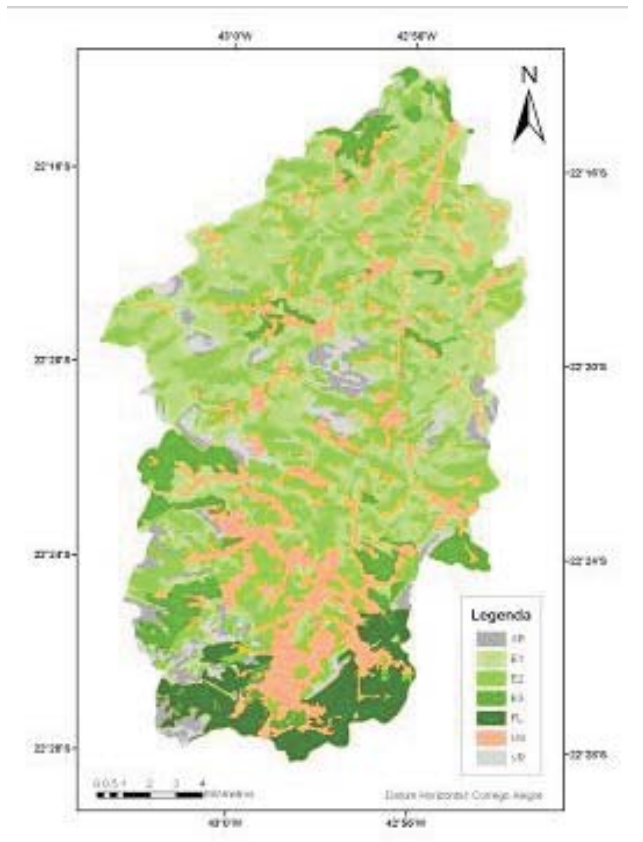

As classes mapeadas da cobertura vegetal na sua formação Floresta Ombrófila Densa são aquelas estabelecidas pelo CONAMA (1994): estágios inicial (E1), intermediário (E2) e avançado (E3) da sucessão ecológica secundária e floresta clímax (FL). Também foi identificada na área a classe de vegetação rupestre, característica de afloramentos rochosos, e que por isso não foi considerada na dinâmica de transformações.

\subsection{Classes de dinâmica}

Neste trabalho foram elaboradas quatro classes para analisar a dinâmica de transformação da cobertura vegetal entre 1976 e 1996 (Tabela 1), bem como considerada uma quinta classe para representar as áreas não modificadas. A classe de regeneração inicial abarcou as áreas que eram de uso antrópico em 1976 e que se tornaram vegetação em estágio inicial ou intermediário em 1996, ou de vegetação em estágio inicial da sucessão ecológica (1976), que se tornaram estágio intermediário (1996). Como regeneração avançada foram designadas as áreas que se tornaram estágio avançado de sucessão ecológica ou floresta clímax em 1996. Todas as classes de vegetação que se converteram para uso antrópico em 1996 foram agrupadas em desmatamento. As áreas

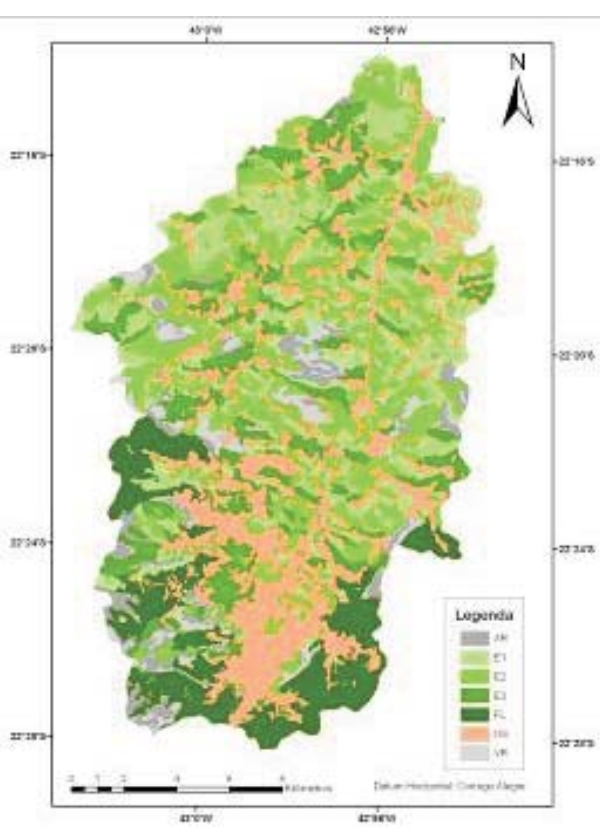

Figura 2 - Distribuição das classes de vegetação e uso do solo em 1976 (A) e 1996 (B), na bacia do rio Paquequer. Fonte/Source: UERJ/IBGE, 1999.

Figure 2 - Vegetation and land use in 1976 (A) and 1996 (B) in Paquequer watershed.

Revista Árvore, Viçosa-MG, v.34, n.6, p.1025-1034, 2010 
Tabela 1 - Classes de dinâmica de transformação da vegetação propostas para análise do período de 1976 a 199.

Table 1 - Vegetation dynamic classes proposed for the period 1976 to 1996.

\begin{tabular}{|c|c|}
\hline $\begin{array}{l}\text { Regeneração } \\
\text { inicial }\end{array}$ & $\begin{array}{l}\text { Uso (1976) que se tornou E1 (1996) } \\
\text { Uso (1976) que se tornou E2 (1996) } \\
\text { E1 (1976) que se tornou E2 (1996) }\end{array}$ \\
\hline $\begin{array}{l}\text { Regeneração } \\
\text { avançada }\end{array}$ & 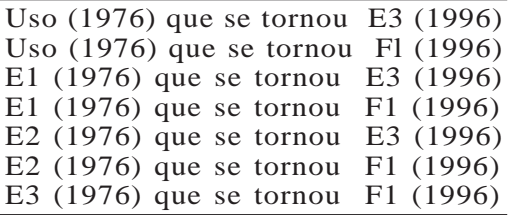 \\
\hline Des & $\begin{array}{l}\text { E1 (1976) que se tornou Uso (1996) } \\
\text { E2 (1976) que se tornou Uso (1996) } \\
\text { E3 (1976) que se tornou Uso (1996) } \\
\text { F1 (1976) que se tornou Uso (1996) }\end{array}$ \\
\hline $\begin{array}{l}\text { Degeneração } \\
\text { da vegetação }\end{array}$ & $\begin{array}{l}\text { E2 (1976) que se tornou } \\
\text { E3 } 1(1976) \text { que se tornou } \\
\text { E2 (1996) } \\
\text { E3 (1976) que se tornou } \\
\text { F1 (1976) que se tornou } \\
\text { E1 (1996) } \\
\text { Fl (1976) que se tornou } \\
\text { Fl }(1976) \text { que se tornou } \\
\text { E1 (1996) }\end{array}$ \\
\hline
\end{tabular}

com cobertura vegetal em estágio superior em 1976, que foram transformadas em estágio inferior em 1996, foram classificadas em degeneração da vegetação.

Foram selecionados os fragmentos com área igual ou superior a 10 ha, uma vez que fragmentos florestais menores que 10 ha são passíveis de sofrer maiores alterações em função de sua área (BIERREGAARD et al., 1992; VIANNA et al., 1992; TABANEZ et al., 1997; ZAÚ, 1997).

\subsection{Análise espacial}

Para a elaboração do Modelo Digital de Terreno (MDT) (Figura 3) foram selecionados os atributos curvas de níveis e pontos cotados da categoria de informação Base Cartográfica (digitalizada da carta topográfica do IBGE na escala 1:50.000) e os canais de drenagem da categoria de informação hidrografia (digitalizada da carta topográfica do IBGE na escala 1:50.000). A rotina empregada foi o Topo to raster da extensão Spatial Analyst do ArcGis 9.0. Essa rotina corrige problemas de interpolação, pois utiliza a rede de drenagem retificada (sentido correto do fluxo d’água), visando aproximarse da melhor forma possível da real superfície topográfica (SILVA, 2006).

A partir do Modelo Digital de Terreno foram elaborados os mapas de declividade e de orientação das vertentes (Aspect). O mapa de declividade foi

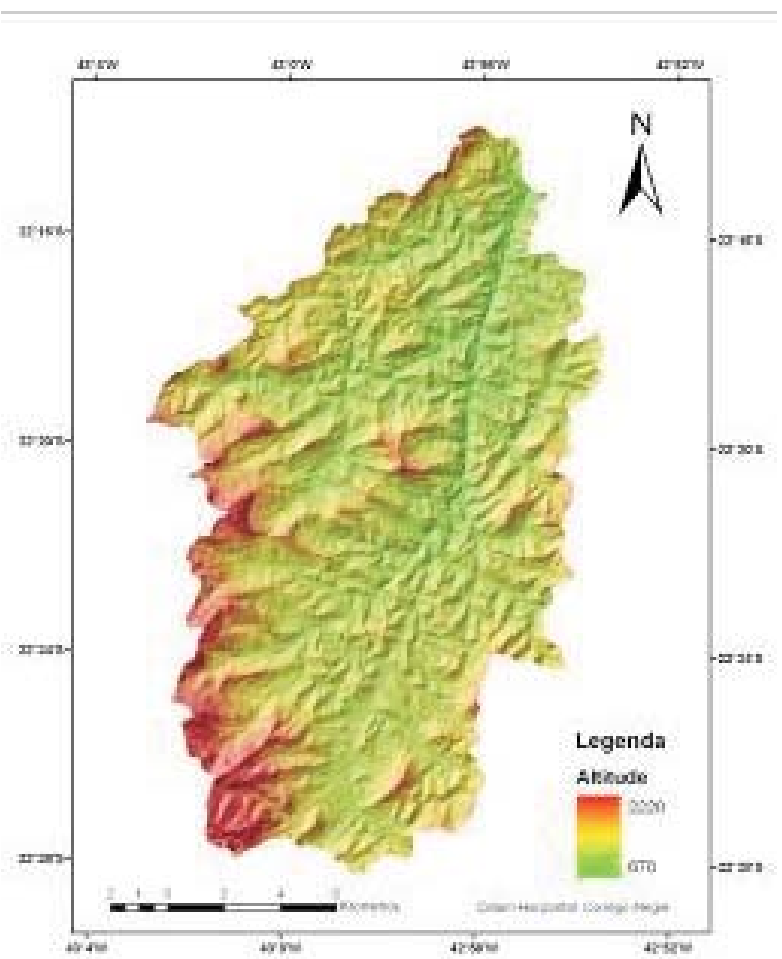

Figura 3 - MDT da bacia do Paquequer. Figure 3 - DEM from Paquequer watershed.

classificado com os seguintes intervalos: < 3\%; 3\% - 8\%; 8\%- 20\%; 20\%-30\%; 30\% - 45\%; 45\% - 60\%; 60\% - $100 \%$ e > $100 \%$. O mapa de orientação das vertentes foi elaborado unificando as seguintes classes de azimute de sentido da linha de maior declividade da encosta: Norte $\left(316^{\circ}-45^{\circ}\right)$, Leste $\left(46^{\circ}-135^{\circ}\right)$, Sul $\left(136^{\circ}-225^{\circ}\right)$ e Oeste $\left(226^{\circ}-315^{\circ}\right)$.

Para analisar a influência da precipitação na dinâmica da vegetação na bacia foram utilizadas as isoietas do total anual das chuvas calculadas pelo CPRM para o Estado do Rio de Janeiro (CPRM, 2004). A rotina empregada foi o Topo to raster da extensão Spatial Analyst do ArcGIS 9.0. Foram individualizadas quatro classes: chuvas anuais menores que 1.500 mm, chuvas anuais de $1.501 \mathrm{~mm}$ a $2.000 \mathrm{~mm}$, chuvas anuais de 2.001 $\mathrm{mm}$ a $2.500 \mathrm{~mm}$ e chuvas anuais maiores que $2.501 \mathrm{~mm}$.

Para a análise da influência dos fatores abióticos sobre a dinâmica de transformação da cobertura vegetal em 20 anos, foram sobrepostas as informações desta com as de declividade, orientação das vertentes e precipitação. Todas as etapas de trabalho foram realizadas com o software ArcGIS 9.0.

Revista Árvore, Viçosa-MG, v.34, n.6, p.1025-1034, 2010 


\section{RESULTADOS E DISCUSSÃO}

\subsection{Caracterização da Cobertura Vegetal}

No cruzamento entre os dados de 1976 e 1996, $76 \%$ da área da bacia apresentou fragmentos maiores que 10 ha. Esse dado indica que a maior parte da bacia está estruturada em fragmentos maiores e, portanto, ecologicamente mais estáveis.

De acordo com as classes estabelecidas para análise da dinâmica das mudanças da vegetação entre 1976 e 1996, 53\% da área da bacia manteve-se na mesma classe de uso/cobertura, e os processos de regeneração ocorreram em 32\% da área. O desmatamento representou $11 \%$ e a degeneração da vegetação, 4\% (Figura 4).

A análise da dinâmica da cobertura vegetal e o uso do solo entre 1976 e 1996 indicam que, concomitantemente ao avanço de áreas de uso antrópico (desmatamento), houve também aumento de áreas de vegetação em estágios inicial e avançado (regeneração inicial e avançada) na Bacia do Paquequer (Figura 4). $\mathrm{O}$ avanço do desmatamento pode ser facilmente compreendido pelo crescimento do Município de Teresópolis. O aumento das áreas de regeneração inicial e avançada foi consequência de processos naturais.

\subsection{Declividade}

A análise do Mapa de Declividade evidenciou o predomínio de relevo forte-ondulado (30\% a 60\%) (Figura 5).

A distribuição das classes de declividade para as classes de regeneração inicial e avançada obedeceu ao mesmo padrão inicial de distribuição de declividade para a bacia, não apresentando controle efetivo nos processos de regeneração. Entretanto, processos de
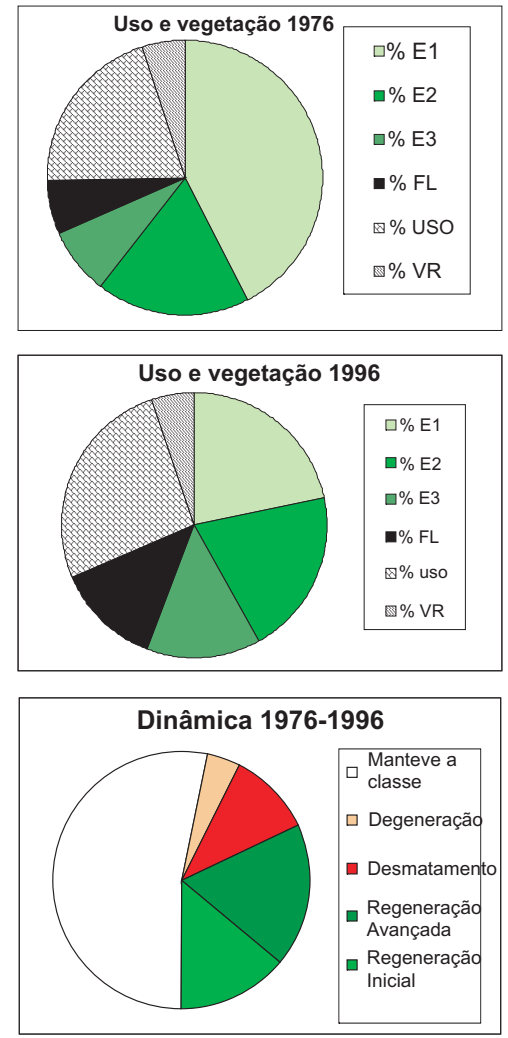

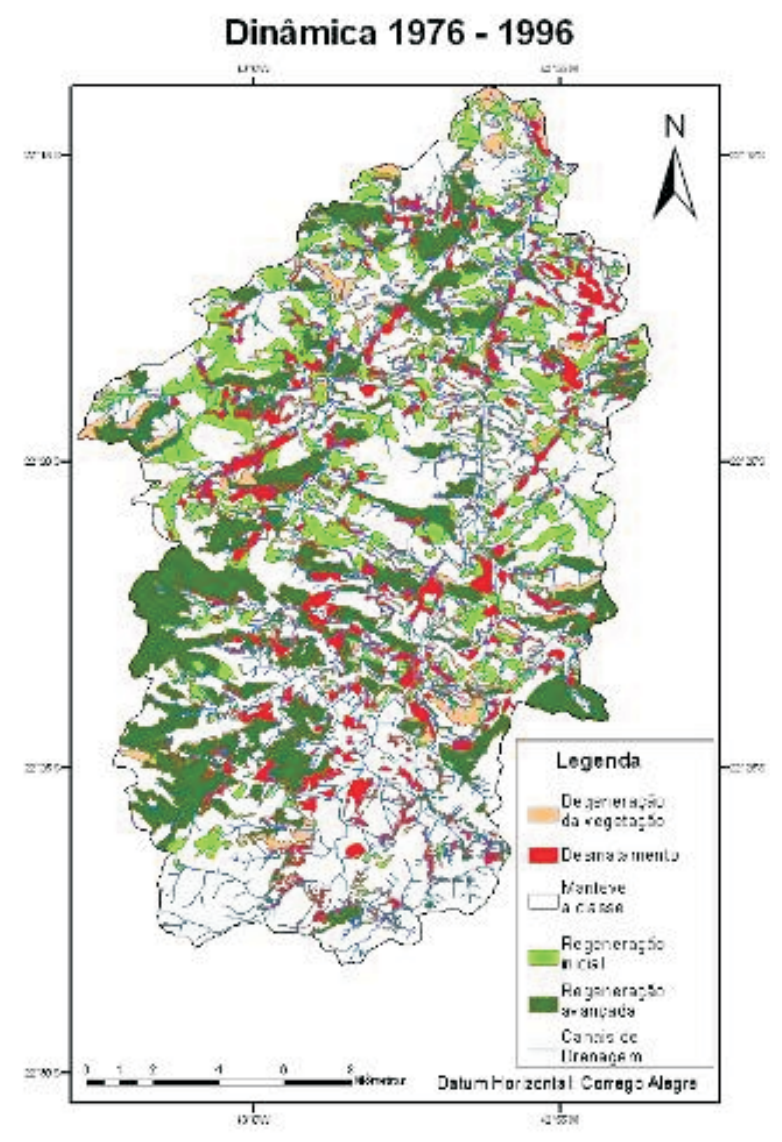

Dinâmica 1976 - 1996

\section{Dinamica $1976-1996$}

Figura 4 - Classes de vegetação, uso em 1976 e em 1996 e dinâmica do uso e da vegetação entre 1976 e 1996, na bacia do Paquequer.

Figure 4 - Classes of vegetation and land use in 1976, 1996 and changes between 1976 and 1996 in Paquequer watershed. 
degeneração da vegetação ocorreram preferencialmente nas maiores declividades (acima de $45^{\circ}$ ), onde os processos erosivos são mais acentuados (Figura 5). Quanto menor a declividade, mais facilmente a vegetação pode-se fixar e obter os água/nutrientes que necessita.

Os resultados mostraram que o desmatamento foi proporcionalmente maior nas áreas de menor declividade (até 20\%), explicando a mudança de tendência nessas classes (Figura 5). Esse comportamento espelhou o avanço do uso antrópico nas áreas mais favoráveis.

\subsection{Orientação das Vertentes}

A análise da orientação das vertentes constitui instrumento eficaz para avaliar o grau de insolação e o nível de umidade, bem como a influência dos ventos sobre aquelas, podendo, portanto, indicar o uso mais
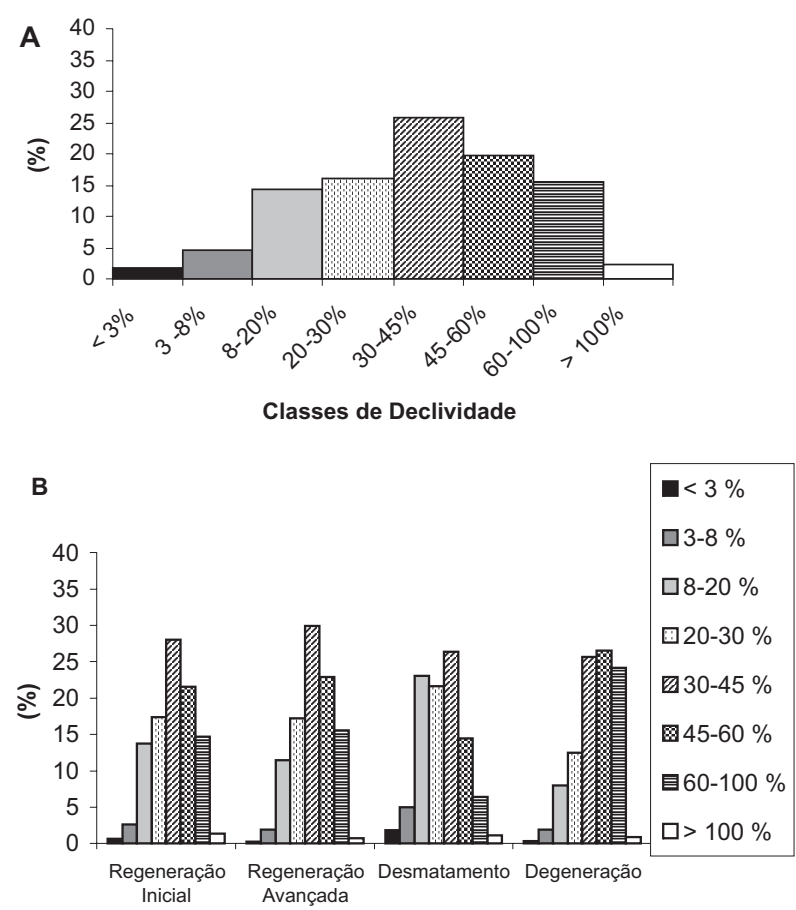

Figura 5 - Classes da declividade em percentagem na bacia do rio Paquequer (A) e cruzamento de declividade com as classes de dinâmica da vegetação/uso (B). Notar que o padrão de declividade é diferenciado para a degeneração (predomínio das classes de maior declividade) e para o desmatamento (predomínio das classes de menor declividade).

Figure 5 - Slope om Paquequer watershed (A) and cross results with vegetation dynamic classes (B). Note a pattern for degeneration (mainly higher slopes) and for deforestation (mainly smaller slopes). adequado. Conforme o movimento aparente do Sol e a inclinação da Terra, no hemisfério sul, as vertentes orientadas para o quadrante Norte recebem maior incidência solar, enquanto aquelas no quadrante Sul recebem menor incidência, sendo, portanto, as vertentes menos privilegiadas quanto à insolação e mais úmidas (HENZ et al., 2003). A análise da distribuição de classes de orientação de vertentes foi equilibrada nas quatro faces: Norte, Sul, Leste e Oeste (Figura 6).

Pelos resultados do cruzamento da dinâmica da cobertura vegetal com a orientação das vertentes, foi possível observar que os fragmentos florestais evoluíram para estágios avançados de regeneração florestal, preferencialmente nas vertentes Sul da Bacia do Rio Paquequer (Figura 6). A orientação das vertentes pode influenciar não só a regeneração, mas, inclusive,

A

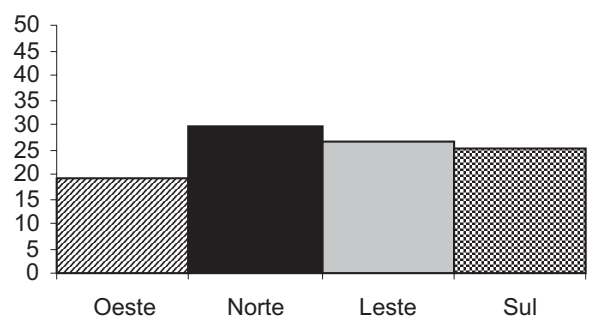

B

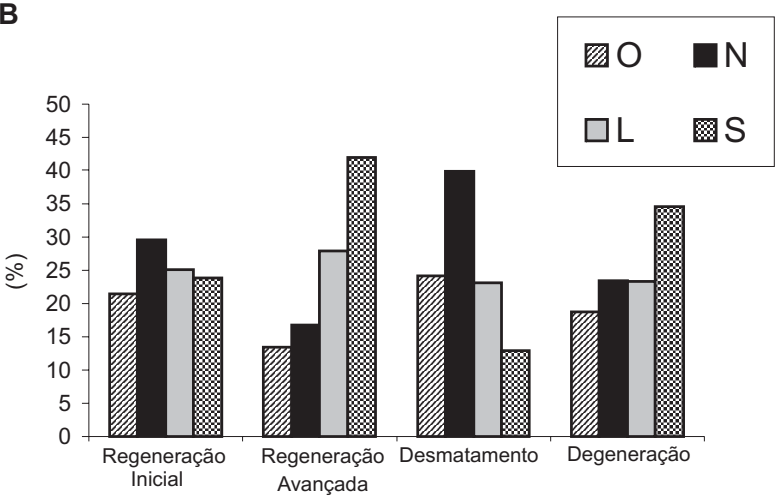

Figura 6 - Orientação das vertentes na bacia do rio Paquequer (A) e cruzamento de orientação de vertentes com as classes de dinâmica da vegetação/uso (B). Notar o padrão de regeneração avançada (encostas sul) e de desmatamento (encostas norte).

Figure 6-Aspect from Paquequer watershed (A) and cross results with vegetation dynamic classes (B). Note a pattern for advanced regeneration (south slopes) and for deforestation (north slopes).

Revista Árvore, Viçosa-MG, v.34, n.6, p.1025-1034, 2010 
a diversidade de espécies. Trabalhos anteriores (OLIVEIRA e MIRANDA, 1983; OLIVEIRA et al., 1995) em levantamentos botânicos realizados no Pão de Açúcar (Rio de Janeiro) encontraram 11 espécies de orquídeas na encosta Sul e apenas duas no lado Norte. Nas encostas Norte da Bacia do Rio Cachoeira (Maciço da Tijuca), a vegetação do sub-bosque foi descrita como mais xeromórfica, enquanto as folhas de espécies das encostas Sul eram geralmente mais tenras e membranosas. Na Bacia do Paquequer, a favorabilidade das encostas voltadas para o Sul só mostrou relevância para os processos de regeneração avançada e não para os de regeneração inicial. Provavelmente, isso seja decorrente da capacidade das classes de vegetação pioneira e de estágio intermediário em suportar condições variadas, enquanto a vegetação clímax e em estágio de sucessão avançado é mais seletiva quanto à umidade e incidência solar.

O desmatamento, entretanto, na bacia ocorreu predominantemente nas vertentes Norte, ou seja, aquelas que recebem maior incidência solar e que são mais quentes, uma vez que Teresópolis tem clima ameno, com temperatura média de $18{ }^{\circ} \mathrm{C}$.

\subsection{Precipitação}

A distribuição anual de chuvas na Bacia do Paquequer varia muito espacialmente (Figura 7). As cabeceiras da bacia são as áreas mais úmidas, com valores anuais maiores que 2.500 mm, enquanto a porção a jusante tem média anual inferior a $1.500 \mathrm{~mm}$. Somente 0,1\% da área de pluviosidade acima de $2.500 \mathrm{~mm}$ modificou a sua dinâmica em 20 anos, sendo classificada em regeneração avançada.

O fator pluviosidade não se mostrou muito importante na definição da dinâmica da vegetação/ uso na bacia. Existe tendência de a regeneração avançada ter sido menos favorecida na classe de chuva $<1.500 \mathrm{~mm}$ anual e da regeneração inicial e a degeneração terem sido favorecidas em condições de menor pluviosidade anual. Na passagem para estágios sucessionais mais avançados, a quantidade de chuva é fator limitante, porque a evapotranspiração é maior que em estágios sucessionais menos avançados. Em casos extremos de condições secas, a vegetação pode chegar até a sofrer estresse hídrico e sofrer degeneração.
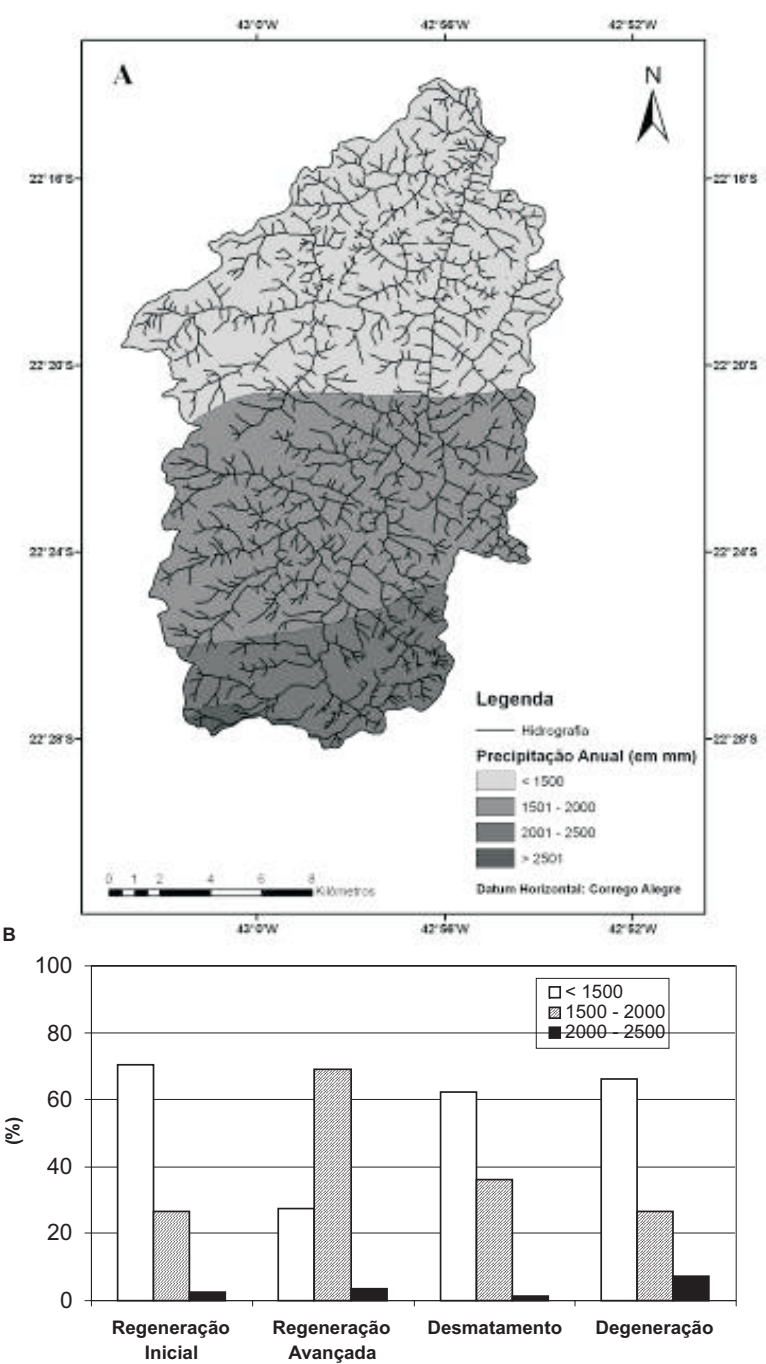

Figura 7 - Mapa da distribuição da precipitação anual na bacia do rio Paquequer (A) e cruzamento de precipitação anual com as classes de dinâmica da vegetação/uso (B). Notar que a regeneração avançada é menos favorecida em condições de baixa pluviosidade anual, ao contrário da tendência da regeneração inicial e da degeneração.

Figure 7-Annual rainfall map from Paquequer watershed (A) and cross results with vegetation dynamic classes (B). Note that advanced regeneration are not favored by smaller annual rainfall classes although initial regeneration and deforestation are.

\section{CONSIDERAÇÕES FINAIS}

Na área da Bacia do Paquequer, entre os fatores abióticos trabalhados, a declividade e, secundariamente, a insolação são os fatores de maior relevância para 
definir a dinâmica das transformações da vegetação ocorridas entre os anos de 1976 e 1996 . A regeneração inicial apresentou-se como um processo relativamente independente dos fatores abióticos. Ou seja, é um processo que ocorre em condições ambientais mais adversas se houver a disponibilidade de um banco de sementes. Fatores antrópicos também influem nessa dinâmica, uma vez que o desmatamento se dá preferencialmente nas encostas mais ensolaradas (voltadas para o Norte) e mais fáceis de serem utilizadas (menor declividade).

A regeneração para estágios mais avançados (E3 e Fl) é um processo mais seletivo (ao contrário da regeneração inicial, que se desenvolve independente das características do meio), ou seja, ocorre preferencialmente em encostas com menor insolação e mais úmidas. A declividade não é fator limitante para a ocorrência de regeneração avançada nessa bacia porque, exatamente nos divisores da área de estudo (alta declividade), existem fragmentos de floresta clímax formados pelas áreas do Parque Nacional da Serra dos Órgãos e Áreas de Proteção Ambiental da Floresta do Jacarandá e da Bacia dos Frades.

Os processos de degeneração são favorecidos em áreas de altas declividades e baixa precipitação anual, caracterizando um possível déficit hídrico.

Com base nos resultados, sugere-se que estudos e iniciativas de gestão de bacias montanhosas sejam baseados nas limitações geoecológicas impostas pelo meio abiótico. Deve-se considerar a maior suscetibilidade da Mata Atlântica em condições de declividade acima de $45^{\circ}$ e nas áreas de pluviosidade anual abaixo de $1.500 \mathrm{~mm}$. Essas áreas representam condições de estresse que podem limitar o desenvolvimento florestal, favorecendo a degeneração natural.

\section{AGRADECIMENTOS}

À FAPERJ, pela bolsa de Pesquisador Associado para a DSc. Carla Semiramis Silveira desenvolver pesquisa no Departamento de Geologia Aplicada da Faculdade de Geologia da Universidade do Estado do Rio de Janeiro; ao CNPq (Processo 478992/2006-8), pelo financiamento; à equipe do LabGis (Laboratório de Geoprocessamento-Departamento de Geologia Aplicada/ Faculdade de Geologia da UERJ), pela edição das figuras; aos dois revisores da Revista Árvore, pelo muito que contribuíram com sugestões para tornar o trabalho mais claro e conciso.

\section{REFERÊNCIAS}

BIERREGAARD, R. O. et al. The biological dynamics of tropical rainforest fragments: a prospective comparison of fragments and continuous forest. Bioscience, v.42 n.11, p.859-866, 1992

BURROUGH, P. A.; MCDONNELL, R. A. Principles of geographical Information systems. Oxford: University Press, 2006. 333p.

CHADA, S. S.; CAMPELLO, E. F. C.; FARIA, S. $M$. Sucessão vegetal em uma encosta reflorestada com leguminosas arbóreas em Angra dos Reis, RJ. Revista Árvore, v.28 n.6, p.801-809, 2004.

COELHO NETTO, A. L. Hidrologia de encosta na interface com a geomorfologia. In: GUERRA, A. J. T.; CUNHA, S. B. (Eds.) Geomorfologia: uma atualização de bases e conceitos. Rio de Janeiro: Bertrand Brasil, 1994. p.93-148.

CONSELHO NACIONAL DE MEIO AMBIENTE - CONAMA. Resolução no 6 de 04 de maio de 1994.

COSTA, D. P. Transformações na dinâmica sócio-espacial urbana da região serrana fluminense: o estudo de caso do distrito sede de Teresópolis. 170f. Dissertação (Mestrado em Geografia) Universidade Estadual Paulista, São Paulo, 2004.

CPRM. Isoietas de distribuição de precipitação para o estado do Rio de Janeiro In: Projeto Rio de Janeiro. Rio de Janeiro: 2004. Disponível em:<http:// www.cprm.gov.br> Acesso em: 07 maio 2007

DUNN, C. P. et al. Methods for analyzing temporal changes in landscape pattern. In: TURNER, M. G.; GARDNER, R. H. (Eds.) Quantitative methods in landscape ecology: the analysis and interpretation of landscape heterogeneity. New York: Springer Verlag, 1991. p.173-198.

FIDALGO, E. C. C. et al. Mapeamento do uso e da cobertura atual da terra para indicação de áreas disponíveis para reservas legais: estudo em nove municípios da região amazônica Revista Árvore, v.27, n.6, p.871-877, 2003.

Revista Árvore, Viçosa-MG, v.34, n.6, p.1025-1034, 2010 
FILGUEIRA LEITE, A. et al. Atuação da biomassa de raízes finas na hidrogeoquímica de uma bacia montanhosa florestada - Parque Nacional da Tijuca, RJ. In: CONGRESSO BRASILEIRO DE GEOQUÍMICA, 6., 1997, Salvador. Anais... Salvador: 1997. p.34-38.

FUNDAÇÃO SOS MATAATLÂNTICA/ INPE. Atlas dos remanescentes florestais e ecossistemas associados da Mata Atlântica no período de 2000-2005. São Paulo: INPE, 2006 Disponível em: <http: www.sosmatatlantica.org.br> Acesso em: 07 maio 2007

GUERRA, A. J. T. Processos erosivos nas encostas. In: GUERRA,A. J. T.; CUNHA, S. B. (Eds.)

Geomorfologia: uma atualização de bases e conceitos. Rio de Janeiro: Bertrand Brasil, 1994. p.149-209.

HENZ, J. et al. Correlação entre orientação das vertentes e uso do solo das bacias hidrográficas Arroio Travesseiro e Sanga do Velocindo-RS. In: SIMPÓSIO BRASILEIRO DE GEOGRAFIA FÍSICA APLICADA, 10., 2003, Rio de Janeiro. Anais... Rio de Janeiro: p.2141-2143.

JORGE, L. A. B.; SARTORI, M. S. Uso do solo e análise temporal da ocorrência de vegetação natural na fazenda experimental Edgardia, em BotucatuSP.Revista Árvore, v.26, n.5, p.585-592, 2002.

NASCIMENTO, M. C. et al. Mapeamento dos fragmentos de vegetação florestal nativa da bacia hidrográfica do rio Alegre, Espírito Santo, a partir de imagens do satélite IKONOS II. Revista Árvore, v.30, n.3, p.389-398, 2006.

OLIVEIRA, R. R.; MIRANDA, F. E. L. Orquídeas rupícolas do Pão de Açúcar. Atas Sociedade Botânica Brasileira, v.1, n.18, p.99-105, 1983.

OLIVEIRA, R. R. et al. Significado ecológico da orientação de encostas no Maciço da Tijuca, Rio de Janeiro. Oecologia Brasiliensis, v.1, p.523-541, 1995.

ROCHA, H. P. A Mata Atlântica e a organização do espaço geográfico na cidade de Teresópolis: planejamento e qualidade de vida. 1999. 130f. Monografia (Especialização em Ciências Ambientais) - Escola Nacional de Ciências Exatas, Instituto Brasileiro de Geografia e Estatística, Rio de Janeiro, 1999.
SILVA, M. C. S. Estudo da sustentabilidade do potencial mineral com utilização de SIG, na bacia hidrográfica do rio Paquequer, município de Teresópolis, RJ. 2004.194f. Trabalho (Conclusão de curso de Geologia) - Universidade Estadual do Rio de Janeiro, Rio de Janeiro, 2004

SILVA, F. A. D. Análise da susceptibilidade a escorregamentos de massas na bacia hidrográfica do Rio Paquequer Teresópolis - Estado do Rio de Janeiro, utilizando os modelos SINMAP e SHALSTAB. 2006. 99f. Dissertação (Mestrado em Geologia) - Universidade do Estado do Rio de Janeiro, Rio de Janeiro, 2006.

SILVA, V. V. et al. Uso do Geoprocessamento como ferramenta para análise geoecológica - o exemplo da bacia do Paquequer. In: CONGRESSO ACADÊMICO SOBRE MEIO AMBIENTE E DESENVOLVIMENTO CADMA, 2., 2006, Niterói. Anais... Niterói: 2006. 14p. CD ROM

SOUZA, A. L. et al. Dinâmica da regeneração natural em uma floresta ombrófila densa secundária, após corte de cipós, reserva natural da Companhia Vale do Rio Doce S.A., Estado do Espírito Santo, Brasil Revista Árvore, v.26, n.4, p.411-419, 2002.

TABANEZ, A. A. J.; VIANA, V. M.; DIAS, A. S. Conseqüências da fragmentação e do efeito de borda sobre a estrutura, diversidade e sustentabilidade de um fragmento florestal de planalto de Piracicaba, SP. Revista Brasileira de Biologia, v.57, n.1, p.47-60, 1997.

UERJ/IBGE. Estudo ambiental como subsídio à metodologia para o ordenamento territorial através de análise de caso: município de Teresópolis, RJ. Projeto PADCT Rio de Janeiro. Rio de Janeiro:1999. 3v.

VIANNA, V. M.; TABANEZ, A. A. J.; MARTINEZ, J. L. A. Restauração e manejo de fragmentos florestais. In: CONGRESSO NACIONAL DE ESSÊNCIAS FLORESTAIS E CONSERVAÇÃO DA BIODIVERSIDADE, 2., 1992, São Paulo. Anais... São Paulo: 1992. p.400-406.

ZAÚ, A. S. A ecologia de paisagem no planejamento territorial. Floresta e Ambiente, v.4, p.98-103, 1997. 